\title{
Wage increases, transfers, and the socially determined income distribution in the USA*
}

\author{
Lance Taylor \\ Arnhold Professor Emeritus, Department of Economics, The New School for Social Research, New York, \\ NY, USA
}

\section{Armon Rezai}

Associate Professor, Vienna University of Economics and Business (WU), Austria, Schrödinger Fellow,** and Research Associate, Vienna Institute for International Economic Studies (WIIW), Austria

Rishabh Kumar

Department of Economics, The New School for Social Research, New York, NY, USA

Nelson Barbosa

Fundação Getúlio Vargas, São Paulo School of Economics, Brazil

Laura Carvalho

Department of Economics, University of São Paulo, Brazil

This paper is based on a social accounting matrix (SAM) which incorporates the size distribution of income based on data from the BEA national accounts, the widely discussed 2012 CBO distribution study, and BLS consumer surveys. Sources and uses of incomes are disaggregated by household groups including the top 1 percent. Their importance (including saving rates) differs markedly across households. The SAM reveals two transfer flows exceeding 10 percent of GDP via fiscal (broadly progressive) and financial (regressive) channels. A third major flow over time has been a ten percentage point increase in the GDP share of the top 1 percent. A simulation model is used to illustrate how 'feasible' modifications to tax/transfer programs and increasing low wages cannot offset the historical redistribution toward the well-to-do.

Keywords: wealth distribution, income distribution, SAM

JEL codes: $D 31, D 33, D 58, B 50$

\section{INTRODUCTION}

In the USA there is ongoing debate about how the positions of the 'poor' (say, households in the bottom one or two quintiles of the size distribution of income), the 'rich' (the top decile or top percentile), and the 'middle class' (households 'between' these

* Financial support for this work came from the Institute for New Economic Thinking, New York, USA. Ongoing comments by Duncan Foley and editorial work by Florentin Glötzl are gratefully acknowledged.

** Granted by the Austrian Science Fund: J 3633. 
two groups) will be affected by fiscal and other initiatives such as raising the minimum wage. Feedbacks of distributive changes into macroeconomic performance are equally of interest. This paper highlights the severe limitations to reducing income inequality in the USA. In model simulations, when they are applied at politically 'feasible' levels, standard policy tools such as increased taxes on high income households, higher transfers to people with low incomes, and raising wages at the bottom do not reduce rich-vs-poor inequality by very much.

The basic reason is that consistent macroeconomic accounting shows that there are three income redistribution flows on the order of 10 percent of GDP. The first two are fiscal tax/transfer payments (broadly progressive) and financial transactions (regressive). The last is an increase over 2 decades by 10 percent of GDP in the share of primary incomes appropriated (some might say expropriated) by the top 1 percent of income recipients. In a macroeconomically consistent framework incorporating the size distribution of income we show that policy interventions such as those mentioned above cannot reverse this historically large and unrequited income transfer.

For ease of presentation the household size distribution is rescaled to the national income and product accounts (NIPA). It is summarized by a metric (the 'Palma ratio') which, as opposed to the standard Gini coefficient, emphasizes the disparity in incomes between the 'poor' (say, households in the bottom one or two quintiles of the size distribution of income) and the 'rich' (the top decile or top percentile). The ratio has trended strongly upward over time.

To trace macroeconomic and distributive linkages through, we use a simple, static demand-driven macro model based on a social accounting matrix (SAM) which enfolds meso-level data on key distributive variables (types of income including transfers received, taxes paid, consumption, saving) for swaths of the size distribution into the NIPA system. Basically, we rescaled available data to fabricate a representation of the size distribution consistent with the NIPA from the US Bureau of Economic Analysis (the BEA accounts are themselves a fabrication). The numbers provide a broadbrush representation of the distributive situation for the period 1986-2009. For the model simulations we focused on 2008, a relatively 'representative' year for the economy. ${ }^{1}$ While the distribution of income for the US economy is well known, there is less clarity on the size distribution of expenditure. As a first approximation we use less granular estimates on consumption and saving rates for most of the population. For the top decile and fractiles (top 10 percent and top 1 percent) we extend the relationship between income and saving using log-linear extrapolation. Our numbers are consistent with other estimations of the size distribution of income, such as the recent study by Alvaredo et al. (2013) and Saez and Zucman (2014). We use a Congressional Budget Office (CBO) study, itself based on administrative tax data, which captures a detailed breakdown of income across a more representative sample of households. Unlike the Survey of Consumer Finances (SCF), there is less concern in this data set regarding oversampling of wealthy households and exclusion of the Forbes 400.

We begin the presentation in Sections 2-4 with a review of the US size distribution in the context of the SAM, shedding light on how relatively large fiscal and financial transfer payments and unequal income flows fit into the macro system. In Section 5, we go on to simulation results, before concluding with a brief discussion in Section 6 . Appendix 1 briefly discusses the Republican 'Path to Prosperity' budget proposal in

1. We choose data for 2008 as they are the most recent. While the economy entered a recession in the second half of 2008, the SAM numbers do not differ significantly from those of 2007. Asset prices do not enter our analysis unless stated explicitly. 
the House of Representatives. Appendix 2 reports details on how we put the accounting together and sets out the specification of the model.

\section{THE US ECONOMY AS A TRANSFER UNION}

To borrow a phrase from Europe, the US economy is a 'transfer union' (though of modest proportion in comparison to European practice). Through both financial and fiscal channels, money flows of well over 10 percent of GDP (or \$1.5 trillion) are transferred among different groups of economic actors. The SAM in Table 1 illustrates the magnitudes scaled to GDP in 2008. The accounting rules are straightforward. Sums of corresponding rows and columns should be equal; the sums of 'institutional' sectors' levels of saving and investment toward the bottom (saving with a positive sign and investment negative) are equal at 18.1 percent of GDP as the condition for overall balance.

The sectors included are households and non-profit institutions, corporate business (non-financial and financial), the overall government sector (Federal, state, and local), and the rest of the world. For accounting purposes a fictional financial sector also appears. It collects interest and dividends disbursed by the other sectors as sources of income in a row and redistributes them in the corresponding column. ${ }^{2}$

The first column of Table 1 gives a cost breakdown of total supply, or GDP plus imports. Supply amounts to 117.9 percent of GDP of $\$ 14.2915$ trillion. The first row shows how it is split among current and capital expenditures (the latter show that households, business, and government all invest in inventories and/or physical capital). Imports are included in the first column as opposed to the first row (with a negative sign) because their costs when they cross the frontier are incorporated into the value of total supply. The other columns and rows respectively present sectoral uses and sources of income.

In the first column, the 'CCA' entries stand for capital consumption allowances or depreciation by sector. They have to be included on the cost side because depreciation makes up part of the investment outlays in the first row.

For the household sector, wages and salaries and employer contributions (to insurance and pension funds) are usually lumped together as 'labor compensation.' Sleight of hand, however, is involved. As highlighted in pale gray, the contributions paid as a cost of employment amount to 10.7 percent of GDP, but then 6.9 percent is passed back to the government (essentially as an employment tax) in its row for contributions received. Wages and salaries alone give a better measure of take-home pay before direct taxes. They make up only 45.8 percent of GDP.

Second, besides the employee contributions, other main sources of government income are indirect taxes (plus minor surpluses of government enterprises) and direct taxes, including 10.6 percent from households (mid-gray highlight). But then in the column for government outlays households receive 12.9 percent of GDP as transfers (mid-gray highlight, in bold font). Although 12.9 percent is small by the European standard of roughly 20 percent, it does signal that a substantial share of GDP is recycled through the direct tax/transfer system. The other major outlay is 16.7 percent of GDP (\$2.387 trillion) for government purchases of goods and services.

Third, the business sector (including financial business) pays 30.9 percent of GDP to the fictional financial sector as interest and dividends (dark gray highlight, white type).

2. In principle the national accounts can always be formulated as a SAM. In practice they are rarely if ever set out in matrix form. We constructed Table 1 from the accounts published by the BEA. 
262 Review of Keynesian Economics, Vol. 5 No. 2

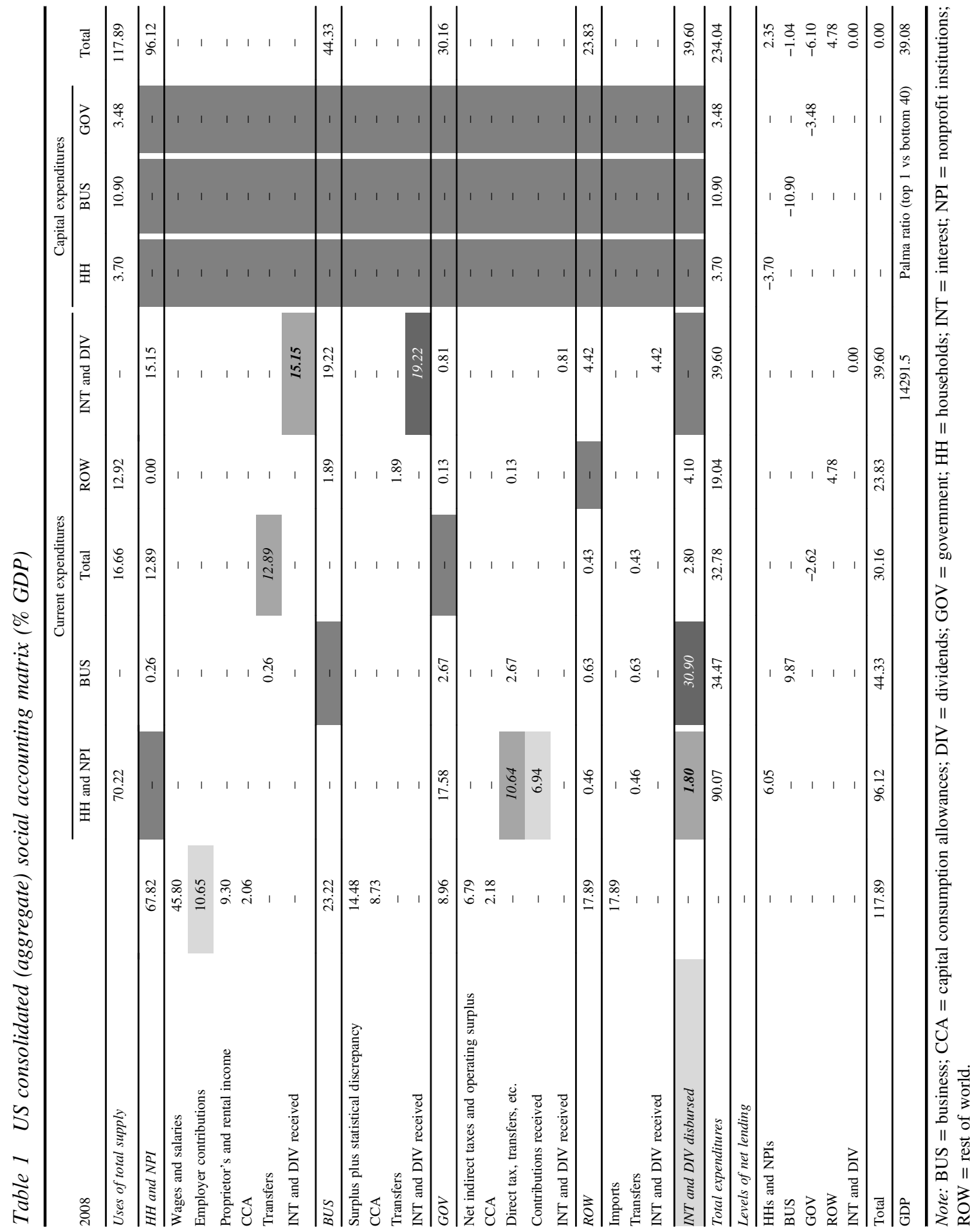


Reflecting the volume of transactions among US financial firms it gets 19.2 percent back (also dark gray). The corresponding numbers in 1986 were 27.3 percent and 17.1 percent, with the increase over 22 years indicating the increasing importance of finance in the economy.

Row 1 of the table shows that the household sector is the other main recipient of financial flows at 15.2 percent (it has a 1.8 percent outlay, shown under 'interest and dividends disbursed by households', mid-gray highlight). In effect there is a net financial transfer from business to households of the same magnitude as the fiscal transfer. As will be seen, the impact of these transfers on the economies of households differs markedly across the size distribution of incomes.

Total government expenditures are 32.8 percent of GDP, while revenues are 30.2 percent, that is, the overall government sector dissaves 2.6 percent of GDP in its row for net lending. Negative government saving is reported as the current deficit in the simulations below. Adding investment expenditure of 3.5 percent boosts government net borrowing or the overall deficit to 6.1 percent of GDP or $\$ 872$ billion on the BEA's reckoning.

The rest of the world's income from US imports is 17.9 percent; its purchases of exports are 12.9 percent. After taking transfers and financial flows into account, 'foreign saving' (or the US current-account deficit) is 4.8 percent of GDP or $\$ 686$ billion.

Looking at the overall picture of net lending flows, the household sector saved more than it invested in 2008 (although the pattern varied notably across the size distribution). Business was a net borrower of 1 percent of GDP.

\section{SIZE DISTRIBUTION AND THE ROLE OF THE TOP 1 PERCENT}

Figure 1 gives a broad-brush picture of the US size distribution of income for 2008, scaled to fit the NIPA numbers in Table $1 .^{3}$ We split households into four groups: those in the bottom two quintiles of the size distribution with a mean income per household of $\$ 42850$ (right-hand scale); those between the 41st and 90th percentiles with a mean income of $\$ 106590$; the 91st to 99th percentiles with $\$ 278320$; and the top percentile at $\$ 2140460$. Sources of income are as in Table 1, that is, wages and salaries, social contributions received, transfers received, and 'other' (including interest and dividends, proprietors' and rental incomes, and capital consumption allowance (CCA), that is, an allowance for capital depreciation).

These income flows do not include capital gains, as these do not figure in the NIPA system. ${ }^{4}$ For the top two groups they generated substantial incomes: $\$ 337700$ for the top 1 percent and $\$ 61600$ for the next group down. Other groups on average received less than $\$ 1000$ (around $\$ 100$ at the bottom). In more prosperous years the top 1 percent got over $\$ 500000$ from this source.

One way of thinking about the degree of inequality in the USA is in terms of a 'Palma ratio' of the mean incomes of the top 1 percent to the bottom 40 percent. ${ }^{5}$

3. As discussed in Appendix 1, we used data from the Congressional Budget Office (2012) report on the size distribution and the Bureau of Labor Statistics (2009) Consumer Expenditure Survey to put together the estimates in the diagram.

4. Capital gains can be inferred from changes of wealth over some period in the flow of funds accounts or directly from income-tax data.

5. In fact, Palma (2011) suggests using the income of the top 10 percent in the numerator, but we chose the top percentile to underline the large degree of inequality in the USA. 
264 Review of Keynesian Economics, Vol. 5 No. 2

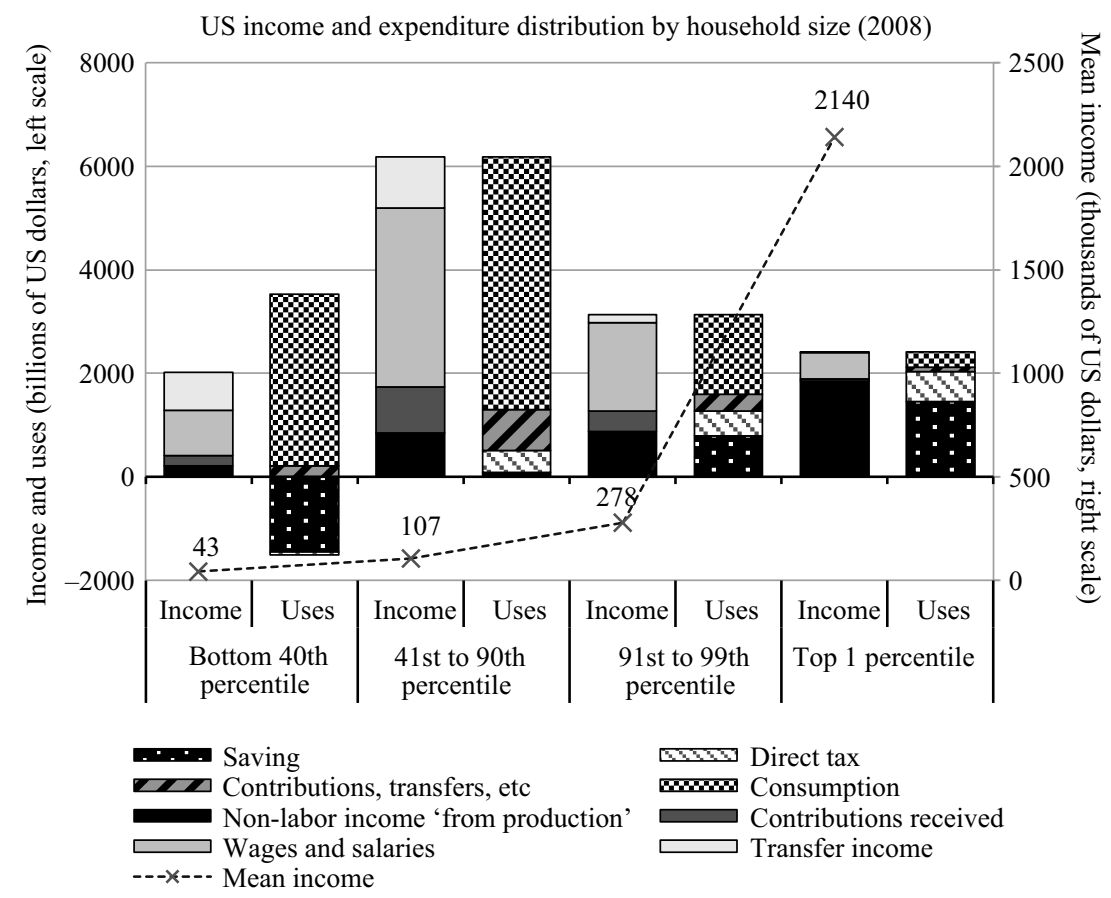

Figure 1 Disaggregation of income and expenditure by type and income groups

While measures of inequality generally rely on Gini estimates, recent emphasis (Alvaredo et al. 2013) has moved towards documenting the income of the top 1 percent. This approach heightens the focus on specific groups and is able to relate the core level of disparity as opposed to average and median statistics regarding the income distribution. Comparing only the top 1 percent with the average person in the economy is itself quite informative in a growing economy if for example they earn several times the median income. But since disparity must measure the absolute 'well-to-do' versus the state of the poorest groups, we appropriately augment the Palma ratio as Top 1 vs Bottom 40. This excludes the middle class (41st-90th percentiles) and salaried professionals (91st-99th percentile). So for example if our measured ratio is 10 , this implies a representative household in the top percentile earns 1000 percent of the income attributable to a representative household in the poorest 40 percent. Figure 2 shows the ratio for disposable income (total income minus social contributions to the government, interest paid out, and direct taxes) on the right-hand scale. The other curves are shares of the four income groups in GDP (left-hand scale).

Note that the top 1 percent steadily increased its share from 5 percent to nearly 15 percent of GDP over 2 decades - the third major transfer mentioned above while shares of the other groups have been stable or have declined.

Our augmented Palma ratio (solid line, right panel) nearly doubled over 2 decades. If 80 percent of capital gains ('post-tax') are added to disposable income, the ratio reached a level of nearly 46 percent before the financial crisis; it dropped off somewhat thereafter (dotted line, right panel). 

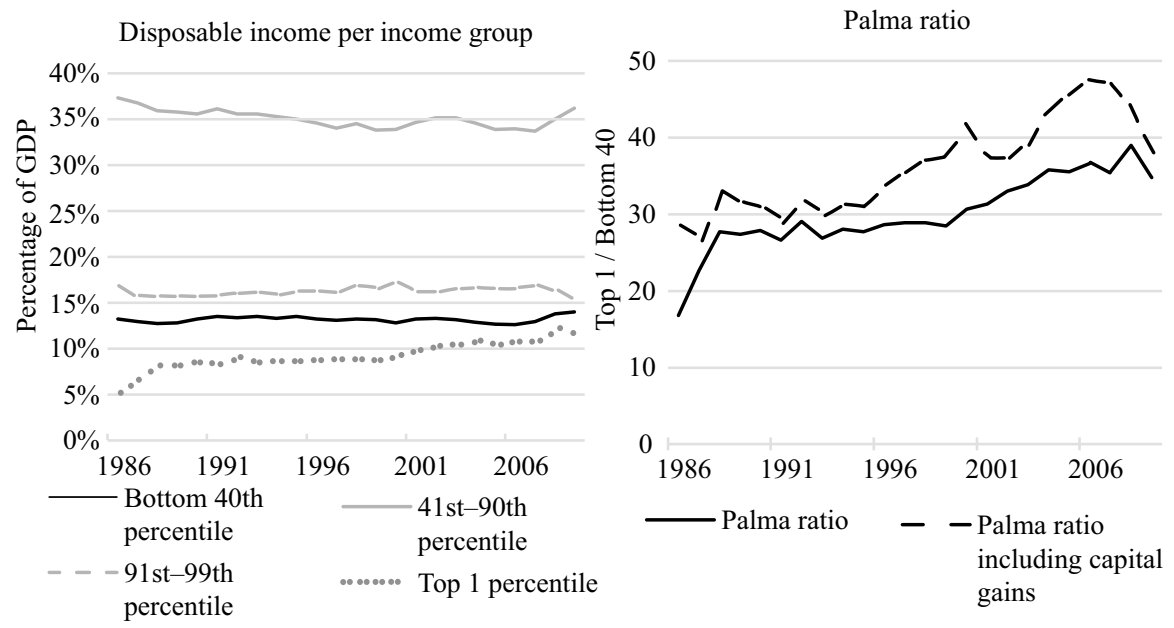

Figure 2 Ratio for disposable income per household (right panel) and the disposable income (total income minus social contributions to the government, interest paid out, and direct taxes) for each income group as a share of GDP (left panel)

Pointing out that income inequality has increased markedly in the USA is scarcely novel. How the current situation fits into national accounting, however, is of considerable interest.

\section{SOURCES AND USES OF INCOME}

Returning to Figure 1, for each group the left-hand bar shows sources of income (again, these estimates are consistent with the totals in Table 1), while the righthand bar indicates how incomes are used. There are striking differences across the income groups.

The 46.9 million households in the bottom two quintiles spend more than they receive. This extra outlay is represented by the segments of their right-hand bar below the horizontal axis, which signal dissaving and negative direct taxes. In the Bureau of Labor Statistics (BLS) consumer expenditure data, the bottom two quintiles have had consistently negative saving levels for 2 decades. There are many plausible explanations - clandestine payments, defaulted personal debt, family support, etc. - but the pattern is clear in the available data. Above the axis, the two outlays are for consumption and social contributions sent to the government in line with Table 1.

On the income side, to the left, poor households receive modest social contributions and non-labor income. The big items are labor income and transfers. Transfers are a bit smaller than wages. Both series have run closely together since 1986 (transfers were larger until 1995).

The pattern for the top 1 percent ( 1.1 million households) is entirely different. Transfers and employer contributions make a minimal contribution to income. Wages and salaries are a significant source (approaching $\$ 500000$ per year) but the lion's share comes from proprietors' incomes and interest and dividends. Both check in at around $\$ 800000$. Uses of income include consumption, social 
contributions, and direct taxes of $\$ 585000$. Saving of roughly 10 percent of GDP accounts for the rest.

In passing, note that there are about 43 times as many low- as high-income households, while the relatively rich have 50 times the average income of the poor. The share of GDP of the top 1 percent is higher than the share of the bottom 40 percent.

For the 58 million middle-class households between the 41st and 90th percentiles, income from labor (wages and contributions) is the dominant source. They also receive transfers (the total is about the same as for the bottom two quintiles) and non-labor incomes. The bulk of their income is devoted to consumption, with modest direct taxes and very low but positive saving.

The pattern for the 91st and 99th percentiles is transitional between the groups on either side. Wages and salaries are their major source of income. Transfers are less important than for the middle class, while non-labor income has a higher share. These 11.3 million households pay more in direct taxes than the middle class, and have positive saving, but consumption still accounts for roughly half of their income.

\section{MODEL DESCRIPTION AND SIMULATION}

To study the effects of policy, we set up a simple comparative static macroeconomic model to obtain a broad understanding of possible impacts of policy changes. Any detailed study would have to take account of the institutional set-up of the US tax and transfer system which, in contrast to Europe where transfers are typically directed through the public sector, are an ad hoc maze of specific programs.

The basic set-up makes output a function of effective demand, with the price level determined by costs. We start our model description on the side of costs, starting with labor. For the USA, one has to deal with the vagaries of labor taxation. The 'basic' wage flow for household group $i$ is $\tilde{W}_{i}$, the sum of 'wages and salaries' and 'employer contributions to employee ... funds' from the SAM. If $\Phi_{i}$ is the ratio of that group's 'employer contributions for government social insurance' to $\tilde{W}_{i}$ then $W_{i}=\left(1+\Phi_{i}\right) \tilde{W}_{i}$ is the total labor cost for group $i$. The corresponding 'wage' or labor payment (total payments received divided by number $L_{i}$ of households in the group) is $w_{i}=\mathrm{W}_{i} / L_{i}$ and $b_{i}=L_{i} / X$. All of this abstracts from household structure, participation rates, etc., which would have to be accounted for in a more detailed model. The groups are defined by the base-year levels of income that define boundaries between boxes such as quintiles, deciles, etc. Tax/transfer policies shift incomes up or down in the boxes, with repercussions on the level of economic activity. Individual households of course may move into or out of a box when their income levels change. Our simulations focus on changes of income levels within boxes, ignoring possible movements across boundaries. Total per unit labor cost faced by business is $Z=\sum w_{i} b_{i}$ with $b_{i}$ constant. $^{6}$

With $P$ being the price of output (not quite equal to the GDP deflator), the overall cost decomposition is

$$
P X=\tau P X+e a P^{*} X+\Xi P X+Z X+\Pi P X,
$$

6. In an alternative specification adopted when low-income $w_{i}$ change, we allow for 'substitution' among different types of labor, so $b_{i}=\gamma_{i}\left[w_{i} / Z\right]^{-\sigma}$ with $Z$ set by a CES cost function $Z=\left[\sum \gamma_{i}\left[w_{i}\right]^{1-\sigma}\right]^{1 /(1-\sigma)}$. In most simulations we assume that the elasticity of substation is zero, $\sigma=0$. 
in which $\tau$ is the ratio of the sum of non-labor indirect taxes (minus subsidies), government CCA, and surplus of government enterprises to output. The exchange rate is $e$, $a$ is the import/output ratio, and $P^{*}$ is a price index for the rest of the world. The term $\Xi P X$ is the sum of household proprietors' income, rental income, and CCA. Indirect taxes, imports, and proprietors' incomes, etc., are assumed to be proportional to output. Total profits are ПРX.

For the baseline scenarios (with zero elasticity of substitution, see also footnote 8), this formulation leads naturally to a mark-up equation for $P$, based on per unit costs of labor and imports:

$$
P=\left(Z+e a P^{*}\right) /[1-\tau-\Xi-\Pi) .
$$

If $\rho=e P^{*} / P$ is an index of the real exchange rate, we add a constant elasticity function for price dependency of the import coefficient

$$
a=\alpha \rho^{-\gamma},
$$

with $\gamma>0$ which can be solved jointly with the cost function to determine the price level in the economy (in the simulations discussed below, $\gamma=0.75$ ). Econometric evidence of minimum wage increases on the aggregate price level suggests very small effects (as compared to price levels of goods of low-wage industries). To capture this low (minimum) wage elasticity of the GDP deflator, the mark-up is endogenized in some simulations by assuming $\Pi=Z_{0} Z^{\Psi_{1}}$ with $\psi_{1}=-0.1$.

With prices specified, we turn to the sectoral income-expenditure accounts, omitting various small items that might be included on one side of the accounts as 'other' net (positive or negative) income or expenditure $O_{i}$.

Aggregate household income is

$$
Y_{H}=\sum Y_{i}
$$

with sources of income for group $i$ as

$$
Y_{i}=w_{i} b_{i} X+\xi_{i} P X+P Q_{i}+U_{i}+O_{i} .
$$

That is, besides 'wages' $w_{i} b_{i} X$, household income includes proprietors' (plus rental and CCA) income $\xi_{i} P X$, the value of 'real' government transfers $P Q_{i}$, financial receipts (interest and dividends) $U_{i}$, and other net receipts $O_{i}$ (from the business and ROW sectors). The condition $\sum \xi_{i}=\Xi$ applies.

Uses of income for group $i$ are

$$
Y_{i}=P C_{i}+\Gamma_{i} \tilde{W}_{i}+P T_{i}+R_{i}+S_{i},
$$

with $C_{i}$ as consumption, $\Gamma_{i} \tilde{W}_{i}$ as the sum of 'employer contributions' (for social insurance) and transfers to government, $P T_{i}$ as direct taxes (so that $T_{i}$ is a 'real' tax level), $R_{i}$ as financial payments, and $S_{i}$ as saving. Transfers, financial receipts, direct taxes, and financial payments are all treated as lump-sum flows. This is the simplest way to treat them and allows us to emphasize the shifts in income distribution. Clearly, they are endogenous in the US economy.

We need consumption functions for the $C_{i}$. The main argument is disposable income,

$$
D_{i}=Y_{i}-\Gamma_{i} \tilde{W}_{i}-P T_{i}-R_{i},
$$

which will be affected by taxes and transfers along with wage levels. 
Aggregate consumption has to equal the sum of consumption over all groups,

$$
C=\Sigma C_{i}
$$

We assume linear consumption functions of the form:

$$
P C_{i}=A_{i}+\left(1-s_{i}\right) D_{i},
$$

with the $s_{i}$ as the group marginal saving rates. The $A_{i}$ and $s_{i}$ parameters were adjusted to fit consumption levels to those in the base-year SAM. In the standard specification, marginal saving rates are set to equal average rates. For the bottom two quintiles, where consumption exceeds income, this implies negative autonomous consumption. In a second specification, saving rates are adjusted to ensure non-negative $A_{i}$.

Business derives income from profits and interest to give

$$
Y_{B}=\Pi P X+U_{B}
$$

Net operating surplus is

$$
N_{B}=Y_{B}-P \Delta_{B}
$$

with $\Delta_{B}$ as real capital consumption plus the statistical discrepancy. Spending is

$$
Y_{B}=N_{B}+P \Delta_{B}=P T_{B}+R_{B}+S_{B}+O_{B},
$$

with $T_{B}$ as direct tax, $R_{B}$ as financial payments, and $O_{B}$ as omitted smaller payments. Saving $S_{B}$ will be the balancing item.

We use an investment function linear in output, output growth, and net operating surplus.

$$
I_{B}=\mathfrak{\imath}_{1} X+\mathfrak{\imath}_{2} N_{B}
$$

with $\imath_{1}=i_{X}+\mathfrak{l}_{g} g_{X}$ capturing the effects of the level and growth of output on business investment described in Fazzari et al. (2008).

Government's income is

$$
Y_{G}=\tau P X+\sum \Gamma_{i} \tilde{W}_{i}+P\left[\sum T_{i}+T_{B}\right]+U_{G}
$$

with $\Delta_{G}$ including the CCA and profits of enterprises. Its uses of income are

$$
Y_{G}=P G+\sum P Q_{i}+R_{G}+S_{G}+O_{G},
$$

with $R_{G}$ as interest payments and $O_{G}$ omitted flows. Saving $S_{G}$ or the fiscal surplus is the balancing item.

Rest-of-world income is

$$
Y_{R}=e a P^{*} X+U_{R}
$$

with the payment $U_{R}$ coming from the financial sector. Its income uses are

$$
Y_{R}=P E+R_{R}+S_{R}+O_{R},
$$

with $R_{R}$ as payments to the financial sector, $O_{R}$ omitted flows, and $S_{R}$ as 'foreign saving' or the current-account deficit. Exports $E$ are a constant elasticity function of unit labor $\operatorname{cost} Z$ (following Storm and Naastepad 2012, we set the elasticity to -0.12 ). 
For the financial sector we have

$$
\sum R_{i}+R_{B}+R_{G}+R_{R}=\sum U_{i}+U_{G}+U_{R}+S_{F} .
$$

In equilibrium the sum of omitted flows has to add to zero,

$$
\sum O_{i}+O_{B}+O_{G}+O_{R}+O_{F}=0 .
$$

To solve the model we need the macro balance relationship

$$
\sum C_{i}+\left(I_{H}+I_{B}+I_{G}\right)+G+E-X=0,
$$

incorporating behavioral relationships for household consumption levels, business and household investment, imports and exports.

It is simplest to treat $G$ and $I_{G}$ (but not government dis-saving $S_{G}$ ) as exogenous policy variables. Multipliers with respect to $G$ are: output, 1.20; fiscal deficit, 0.90; trade deficit, 0.18. All values are in the conventional range for simple demand-driven models.

Nominal GDP can be defined as

$$
V Q=\left(P-e P^{*} a\right) X=(P-a) X,
$$

with $V$ as the GDP deflator; $X, P$, and $a$ as levels of output, price, and the import/output coefficient in any simulation; and $e=P^{*}=1$ initially. Real GDP is

$$
Q=(1-a) X
$$

so the deflator becomes

$$
V=(P-a) /(1-a) .
$$

These equations fully specify the economy at sectoral detail. All parameters are taken from our extended national accounts. The consumption and investment functions are behavioral equations closing the system and are explained above. While our treatment of distribution is highly aggregated, some insights can be gleaned nonetheless. Table 2 presents macro-level impacts of shocks to the system. Table 3 shows distributive implications for disposable incomes and numbers of households. We consider the impacts of fiscal expansion (without and with higher taxation), higher taxes linked with increased transfers, and wage increases for low-income groups.

As emphasized in connection with Figure 1, there are big differences across the size distribution in household saving behavior: average rates are negative at the bottom and positive at the top. The simulations reported here are all based on average saving rates. Modifications such as setting the marginal saving rate to zero at the bottom do not affect the results very strongly.

Row B in the Tables 2 and 3 shows the effects of an increase of 100 (billion dollars) of government purchases of goods and services from an initial level of 2381. GDP increases by 102, signaling a modest multiplier for GDP (the multiplier for total supply is 1.2). Both the fiscal and foreign deficits go up. ${ }^{7}$ On the distributive side, numbers of households in all groups increase - this response is a proxy for higher employment generated by fiscal spending. An increase in ' $G$ ' of 4.1 percent generates a rise of

7. Recall from the discussion above that the numbers in Table 1 report the current fiscal deficit at a level of 374.6 in the base year. Adding investment spending of 497.2 sets overall government borrowing to 871.8 or 6.1 percent of GDP. 
270 Review of Keynesian Economics, Vol. 5 No. 2

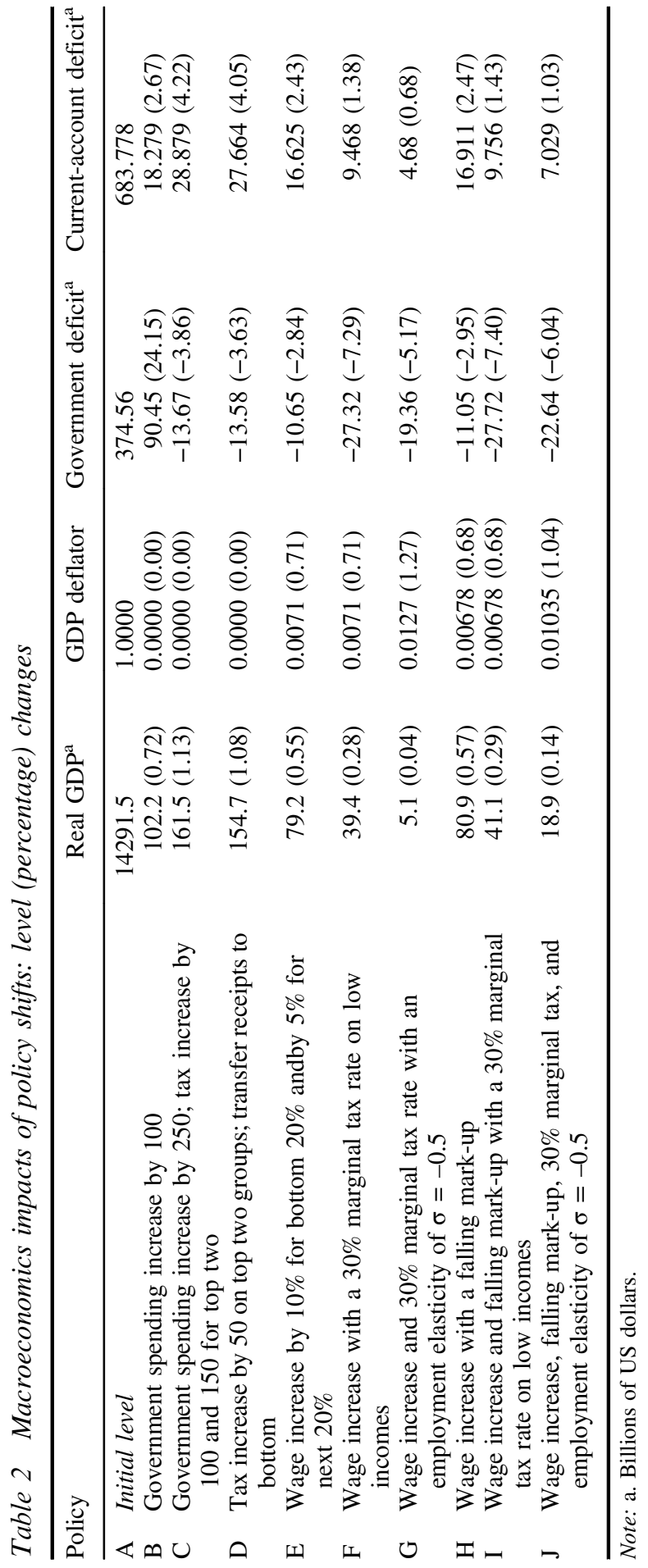


Wage increases, transfers, and the socially determined income distribution in the USA 271

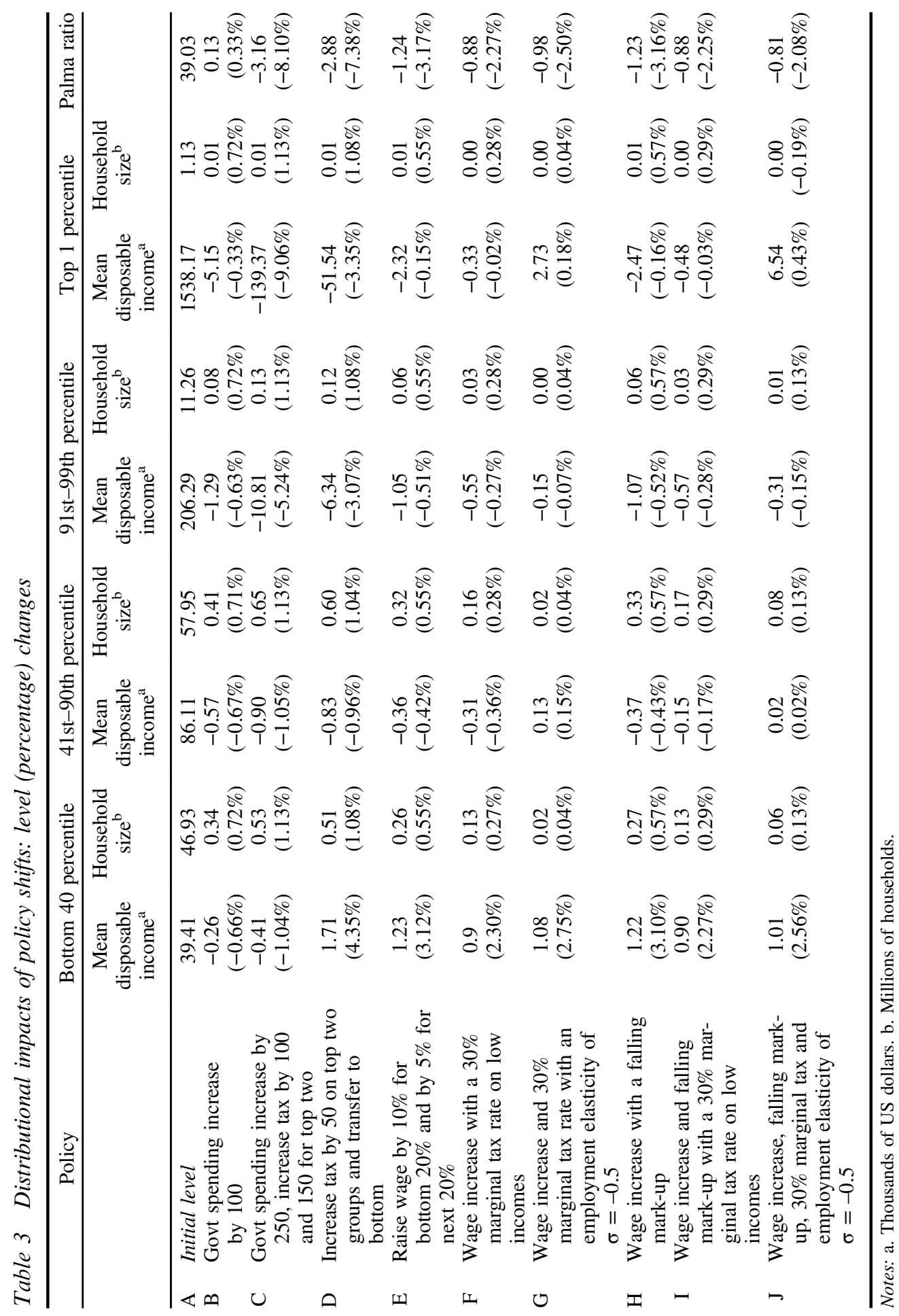


0.7 percent in 'employment,' again a modest increment. The model specification treats direct taxes and transfers as lump-sum, fixed in real terms. Hence the percentage increases in mean disposable incomes for each group are less than total incomes, leading to a modest average income loss across the board. ${ }^{8}$

The highest-income households and the group just below pay direct taxes of 586 and 490 respectively (a total of 1076). Suppose that their (lump-sum) direct taxes are increased by $20+$ percent to 150 and 100, 'offset' by an extra 250 in government spending (a 10.5 percent increase). Row $\mathrm{C}$ in Table 2 shows that GDP expands and the fiscal deficit decreases. In Table 3, employment rises while mean disposable income goes down for all four income groups (in part for the reasons discussed above). The decrease of 9 percent for the richest group is especially visible and the Palma ratio falls by 8 percent. This simulation focuses on reducing inequality by cutting disposable incomes at the top. A 20 percent tax hike, however, may well be politically out of bounds as of 2014, even though it could readily be based on wealth, capital gains, or the large financial flows illustrated in Table 1. On the other hand, a 9 percent reduction in income due to the tax increase does not go very far toward offsetting the 300 percent increase in real average income that the top 1 percent enjoyed between 1986 and 2008.

Row D shows the effects of a more modest tax increase at the top combined with a revenue recycling through higher transfers to low income groups, that is, taxes are raised on high savers' incomes and transferred to groups with negative saving. This package is expansionary, raises disposable incomes at the bottom, and reduces incomes at the top. It cuts the fiscal deficit. A larger version would cut further into the Palma ratio by reducing the numerator and raising the denominator. Taxing the rich by offsetting transfers to the poor looks like an effective means to ameliorate inequality overall. Nevertheless, the Palma metric does not fall by very much. Raising transfers to the bottom from 708 toward a 'European' level of 1100 would require a 50 percent tax hike at the top, imposition of a value-added tax, or perhaps a combination thereof.

In contrast, row E concentrates on the denominator in the Palma index by raising money wages for the bottom two quintiles (by 10 percent at the bottom and 5 percent for the second quintile), broadly in line with the minimum wage increases analysed by the Congressional Budget Office (2014). In Table 2 there is a 0.55 percent increase in real GDP owing to higher consumption demand and the GDP deflator goes up by 0.7 percent. Table 3 reports a 3 percent increase in disposable income for the bottom two quintiles, with the other groups decreasing slightly. The Palma ratio falls from 39 to a bit less than 38. Potential offsets to the wage increase should also be considered.

The US transfer system effectively 'taxes' income increases at the bottom of the size distribution by reducing benefits. A rough estimate of the tax rate is 30 percent (Congressional Budget Office 2014). Row F in the tables shows that the low-income wage increase is less expansionary and redistributive when this limitation is taken into account.

The usual objection to a minimum wage increase is that firms will cut back on employment (or raise labor productivity) in response. Row $\mathrm{G}$ shows that bringing this possibility into play reduces increases in GDP and employment. Because of the latter effect, the average disposable income of the bottom group goes up.

8. The specification is not unreasonable. Many households in the bottom two quintiles rely on pre-fixed income transfers such as social security. Over time, presumably disposable income would rise more or less in line with GDP as transfers ratchet up. 
Firms might also adjust to the wage increase by reducing mark-ups. Row $\mathrm{H}$ shows stronger expansion, less inflation, and stronger real income gains.

All effects are combined in row J. Raising low-income wages appears to be beneficial, but in overall macroeconomic terms the changes are minimal, in the range of a few percent of initial levels of the relevant variables.

\section{DISCUSSION}

The observation that the macroeconomic effects of redistributive policy are minimal illustrates the fundamental finding of this paper. Policy initiatives within 'feasible' limits will not strongly affect distribution in the US economy. Modifying taxes and transfers within the 10 percent of output that could be manipulated by the government or increasing wages at the bottom by 10 percent (or even 20 percent) simply cannot offset the shift of 10 percent of GDP toward the top income group that occurred after the 1980s. ${ }^{9}$ Only major social changes - such as changes in the ownership structure, expropriating the expropriators in the ancient phrase - could begin to accomplish that task.

\section{REFERENCES}

Alvaredo, Facundo, Anthony B. Atkinson, Thomas Piketty, and Emmanuel Saez (2013), 'The top 1 percent in international and historical perspective,' NBER working paper 19075, National Bureau of Economic Research.

Congressional Budget Office (2014), 'The effects of a minimum-wage increase on employment and family income,' available at: http://www.cbo.gov/publication/44995.

Dynan, Karen E., Jonathan Skinner, and Stephen P. Zeldes (2004), 'Do the rich save more?' Journal of Political Economy, 112(2), 397-444.

Fazzari, Steven, Piero Ferri, and Edward Greenberg (2008), 'Cash flow, investment, and KeynesMinsky cycles,' Journal of Economic Behavior and Organization, 65, 555-572.

Palma, José Gabriel (2011), 'Homogeneous middle vs. heterogeneous tails and the end of the "inverted U": it's all about the share of the rich,' Development and Change, 42, 87-153.

Saez, Emmanuel and Gabriel Zucman (2014), 'Wealth inequality in the United States since 1913: evidence from capitalized income tax data,' NBER working paper 20625, National Bureau of Economic Research.

Storm, S. and C.W.M. Naastepad (2012), Macroeconomics beyond the NAIRU, Cambridge, MA: Harvard University Press.

\section{APPENDIX 1 'THE PATH TO PROSPERITY'}

Row D in Tables 2 and 3 illustrates the effects of raising taxes on high savers at the top of the size distribution and transferring money to low savers at the bottom. The Republican 2015 budget proposal in the House of Representatives follows the opposite course. On an annual basis the basic idea is to cut transfers across the board by about 500 (billion) and to cut taxes for the top two groups by 50 each.

9. This observation is not model-specific. Given the accounting underlying Table 1 and Figures 1 and 2, even a highly neoclassical model would give outcomes similar to those reported here. 
The transfer reduction is impressive at 27 percent of the initial level; the tax cuts are around 10 percent.

No surprise, in a demand-driven model GDP falls by about 5 percent. The current government deficit drops from 374.6 to 38 . To get to a 'balanced budget' or zero government net borrowing (= current saving minus investment) there would have to be a reduction of 690 (29 percent) in current government spending. GDP would end up falling by 9 percent.

These numbers show that the 'Path to Prosperity' leads toward Depression, as it must in an economy in which expenditure determines income. Presumably prosperity could be created if reduced net borrowing by the government were to flow automatically into higher capital formation and growth. Despite the House majority's faith in Say's law, capitalist economies don't work that way.

\section{APPENDIX 2 NATIONAL ACCOUNTING AND SIZE DISTRIBUTION OF INCOME}

Based on the sources summarized in Table A1, the construction of a data set that integrates the size distribution into the NIPA took place in seven steps.

1. Annual data from the NIPA system were restated as social accounting matrixes (or SAMs). In principle it should be straightforward to restate national accounts in the form of a SAM, but this step is not normally taken by the Bureau of Economic Analysis.

2. The CBO definitions of income flows were adjusted for rough consistency with the definitions in NIPA (the major arbitrary assumption was to assign one-half each of 'other income' flows to financial incomes and wages). The CBO definition for other income predominantly captures retirement income or income received from other sources. A 50 percent allocation to financial receipts and wages is a reasonable imputation based on contemporary pension and mutual funds plans. By itself, the contribution of this category is less than 10 percent across groups and time. Our robustness checks using alternate simulations do not significantly alter our results.

3. For each year in the sample, shares of total incomes (including transfers) and taxes for the seven household categories were calculated as ratios of flows at the group level to the corresponding totals in the CBO data set.

4. These income shares were then applied to each year's NIPA totals of wages, transfer, financial, and proprietors' incomes to estimate flow levels for the seven income groups. A NIPA-consistent distribution of total income across groups also came out of this calculation.

Table A1 Data sources

\begin{tabular}{ll}
\hline Source & Website \\
\hline CBO (2012) & http://www.cbo.gov/publication/43373 \\
BEA (2009) & http://www.bea.gov/iTable/index_nipa.cfm \\
BLS (2009) & http://www.bls.gov/cex/csxstnd.htm\#2009
\end{tabular}

Note $: \mathrm{CBO}=$ Congressional Budget Office; BEA = Bureau of Economic Analysis; BLS = Bureau of Labor Statistics. 
5. CBO-based shares were used to distribute total NIPA outlays for direct taxes, social insurance, and finance across all seven groups.

6. Shares of total consumption by quintile (adjusted to be consistent with NIPA definitions) from the BLS data were calculated, and then applied to NIPA total consumption. Saving flows by quintile could then be calculated as the differences between income levels and outlays for consumption, finance, and taxes.

7. Saving data by quintile were extrapolated to estimate levels for the 81-90-percent and 91-99-percent groups with weights based on income size (higher income means more saving). This assumption is consistent with Dynan et al. (2004): the rich save more. Consumption and saving are the only categories not available at the granularity demanded by our household categories. Since we have aggregate saving for the top quintile and our estimations yielded numbers for all but the top 1 percent within this group, we attributed residual savings to the latter (Top 25 th percentile -81 st to 99 th percentile). Since the numbers are scaled using NIPA aggregates, we do not capture savings and capital gains separately. However, we remain within the usual bands of saving propensities seen in other literature such as Dynan et al. (2004) and Saez and Zucman (2014). Even topcoded survey data utilized by the former yield a 25 percent saving rate for the top quintile. By our measures, the 81st to 90th percentile make savings of 21 percent, while the corresponding numbers in 2008 for the 91st to 99th percentile are 33 percent. 